\title{
Influence of subject characteristics on DTI parameters in the normal heart
}

\author{
Laura-Ann McGill ${ }^{1 *}$, Pedro Ferreira ${ }^{1}$, Andrew D Scott ${ }^{1}$, Sonia Nielles-Vallespin² ${ }^{2}$ Tevfik Ismail ${ }^{1}$, Ranil Silva ${ }^{1}$, \\ Philip J Kilner ${ }^{1}$, David Firmin ${ }^{1}$, Dudley J Pennell ${ }^{1}$ \\ From 17th Annual SCMR Scientific Sessions \\ New Orleans, LA, USA. 16-19 January 2014
}

\section{Background}

Myocardial disarray is considered an important histological feature of hypertrophic cardiomyopathy (HCM)[1]. In vivo Cardiac Diffusion Tensor Imaging (cDTI) offers the potential to detect myocardial disarray and describe mean intravoxel myocyte orientation; however to date there is little quantitative cDTI data in the normal heart. In this study, we aim to establish the impact of physical and cardiac characteristics on cDTI parameters in a cohort of healthy volunteers.

\section{Methods}

We recruited 46 healthy volunteers for cDTI at $3 \mathrm{~T}$. Three short axis mid-ventricular slices were acquired with multiple breath holds at the systolic pause. Data was post-processed with a platform, developed in-house, to create Fractional anisotropy (FA), Mean diffusivity (MD) and Helical Angle (HA) maps.

\section{Results}

Two of the original 46 volunteers were excluded due to ECG irregularities. Data was successfully acquired in the remaining 44 volunteers (table 1 ). FA, MD and global endocardial HA values were found to be independent of subject age, sex, body surface area (BSA), indexed left ventricular end diastolic volume (LVEDVi) and indexed left ventricular mass (LVMi). There was a significant correlation between age and the global epicardial HA $(\mathrm{r}=0.56, \mathrm{p}<0.001)$ with a gradual decline in leftward HA angulation with increasing age (Figure 1). This correlation persisted after adjusting for ventricular length $(\mathrm{r}=0.45, \mathrm{p}=0.002)$ and BSA $(\mathrm{r}=0.42, \mathrm{p}=0.004)$. There were also significant correlations between global

${ }^{1}$ The Cardiovascular BRU, Royal Brompton Hospital, London, UK Full list of author information is available at the end of the article epicardial HA and lateral mitral annular plane systolic excursion (MAPSE) ( $r=-0.473, \mathrm{p} 0.001)$, and between lateral MAPSE and age $(r=-0.375, p=0.012)$ suggesting that the association between age and HA may be mediated through age related reduction in lateral MAPSE.

\section{Conclusions}

Our data suggests that the cDTI parameters FA and MD, which describe intravoxel myocyte organisation and average myocardial diffusivity respectively, are independent of physical characteristics in healthy subjects. However, there is an association between age and epicardial HA which may be the result of age related loss in longitudinal function[2]. Future work will consider

Table 1

\begin{tabular}{cc}
\hline Baseline Characteristics & $\mathbf{N}=\mathbf{4 4}$ \\
\hline Age: yrs (range) & $45(24-74)$ \\
\hline Male subjects & $27(61 \%)$ \\
\hline BSA: $\mathrm{m}^{2}$ & $1.88 \pm 0.20$ \\
\hline BMI: $\mathrm{kg} / \mathrm{m}^{2}$ & $24.5 \pm 2.95$ \\
\hline LVEDVi: $\mathrm{mL} / \mathrm{m}^{2}$ & $77.5 \pm 13.9$ \\
\hline LVMi: $\mathrm{g} / \mathrm{m}^{2}$ & $64.0 \pm 17.0$ \\
\hline LVEF: $\%$ & $68 \pm 6$ \\
\hline Ventricular length in diastole: $\mathrm{mm}$ & $95.2 \pm 8.56$ \\
\hline DTI parameters & $0.93 \pm 0.14$ \\
\hline MD global: $\times 10^{-3} \mathrm{~mm}{ }^{2} / \mathrm{s}$ & $0.47 \pm 0.05$ \\
\hline FA global & $34 \pm 5$ \\
\hline Endocardial HA global: & $-2 \pm 3$ \\
\hline Mesocardial HA global: & $-35 \pm 5$ \\
\hline Epicardial HA global: &
\end{tabular}




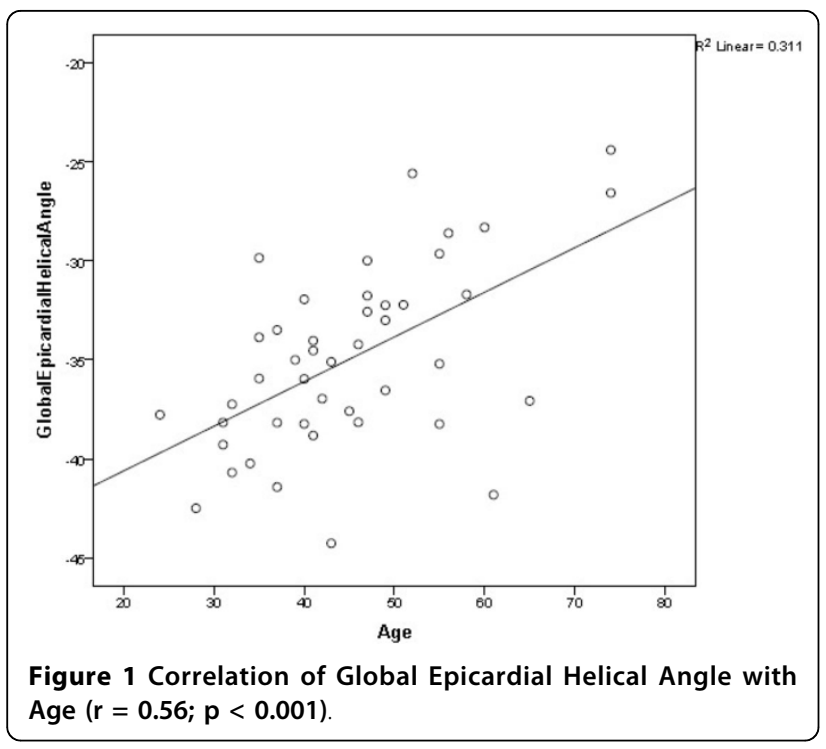

the importance of technical factors such as a SNR and myocardial strain, which may vary with body habitus.

\section{Funding}

NIHR cardiovascular BRU Royal Brompton Hospital \& Imperial College.

\section{Authors' details}

${ }^{1}$ The Cardiovascular BRU, Royal Brompton Hospital, London, UK. ${ }^{2}$ National Heart, Lung and Blood Institute., National Institute of Health, Bethesda, Maryland, USA.

Published: 16 January 2014

\section{References}

1. Maron BJ: Circulation 1979, 59:689-706.

2. Innelli : Eur J Echocardiogr 2008, 9:241-249.

doi:10.1186/1532-429X-16-S1-P7

Cite this article as: McGill et al:: Influence of subject characteristics on DTI parameters in the normal heart. Journal of Cardiovascular Magnetic Resonance 2014 16(Suppl 1):P7.
Submit your next manuscript to BioMed Central and take full advantage of:

- Convenient online submission

- Thorough peer review

- No space constraints or color figure charges

- Immediate publication on acceptance

- Inclusion in PubMed, CAS, Scopus and Google Scholar

- Research which is freely available for redistribution

Submit your manuscript at www.biomedcentral.com/submit 